\title{
Una manera de optimizar un portfolio financiero
}

\author{
María Magdalena Mas \\ Profesora de Matemática \\ Profesor Adjunto Ordinario de la cátedra de Matemática Básica de la \\ Facultad de Ciencias Económicas de la Universidad Nacional del Litoral \\ Email:mmmas@fce.unl.edu.ar
}

\section{Resumen}

Este trabajo es el informe final del curso de Posgrado de Matemática y Finanzas con Matlab, dictado por el Dr Carlos Neuman en el marco de la Maestría de Matemática de la Facultad de Ingeniería Química de la Universidad Nacional del Litoral.

El tema que se aborda en éste trabajo es la Optimización de un Portfolio de acciones tomando como datos el Superfondo de Acciones del Banco Santander; cuyo objetivo es estudiar los aspectos matemáticos del problema de 0ptimización de Portfolios aplicando la teoría de Markowitz y utilizando el Matlab.

La metodología está basada en un diseño cualitativo, de investigación documental no estadística, teórica. En una primera etapa, la investigación se inició como exploratoria, para luego transformarse en descriptiva.

Se trata además de una investigación orientada a la aplicación. De carácter no experimental, dado que se observan fenómenos "económicos" como se dan en su contexto natural para después analizarlos.

En un primer momento se indaga sobre los conceptos básicos referidos a las Finanzas formando un Glosario (que se adjunta al final del trabajo). Luego se investiga específicamente sobre el Modelo de Markowitz. En un tercer momento se analizan las funciones propias de Finanzas en el

Palabras clave

- Portfolio

- Optimización

- Matlab Matlab. Por último se aplica lo estudiado a un caso concreto. Como resultado se obtuvo la conformación de un portfolio óptimo, donde se logra la mayor rentabilidad para un nivel de riesgo mínimo acordado. 